\title{
La imagen del menor en la cobertura fotoperiodística de conflictos armados. El caso de la prensa generalista de España
}

\author{
Carlos MACIÁ-BARBER \\ Universidad Carlos III de Madrid \\ carlos.macia@uc3m.es
}

Recibido: $13 / 11 / 2012$

Aceptado: 14/05/2013

\section{Resumen}

El objetivo de la investigación es averiguar las características específicas del tratamiento fotoperiodístico de la prensa española de información general en la cobertura informativa de los conflictos armados cuando aparecen menores de edad. Para precisar esos rasgos se analizaron mediante 29 variables las 111 fotografías de esa naturaleza que se publicaron durante 2010 en El País, El Mundo, Abc, La Vanguardia, Qué! y 20 minutos. La niñez se convierte en intencionado icono de las víctimas de la violencia, en especial en el imaginario de los conflictos palestino-israelí y afgano. Las instantáneas, distribuidas por agencias de información internacionales, homogeneízan la visión de las contiendas, vulneran por lo general el derecho a la imagen de sus protagonistas y transgreden principios asentados de la deontología profesional.

Palabras clave: Conflicto armado, fotoperiodismo, menor de edad, prensa, España

\section{Photojournalism, Armed Conflicts and Minors in the Newspapers of Spain}

\begin{abstract}
The aim of the research is to find out the specific characteristics of the journalistic treatment of the photography in which appear minors regarding the news coverage of armed conflicts in some of the most relevant newspapers of Spain (El País, El Mundo, Abc y La Vanguardia) and the main free papers (Qué!, 20 minutos). The analysis using 29 variables includes the 111 pictures spread during 2010. Childhood, converted intentionally in icon of victims of violence, appears consistently in the images, especially with regard to Palestinian-Israeli and Afghanistan conflicts. Snapshots, regularly distributed by the international press agencies, mostly violate the right to the own image of the protagonists, infringe settled principles of the journalistic ethics and homogenized vision of the reality.
\end{abstract}

Keywords: Armed Conflict, Photojournalism, Minor, Press, Spain

\section{Referencia normalizada}

MACIÁ-BARBER, Carlos (2013): "La imagen del menor en la cobertura fotoperiodística de conflictos armados. El caso de la prensa generalista de España". Estudios sobre el Mensaje Periodístico. Vol. 19, Núm. 2 (julio-diciembre), págs.: 751-766. Madrid, Servicio de Publicaciones de la Universidad Complutense.

Sumario: 1. Fotoperiodismo, violencia y menores. 2. Objetivo e hipótesis. 3. Metodología. 4. Análisis de los resultados; 4.1. Señalada y arbitraria aparición del menor como víctima-testigo del conflicto armado; 4.2. Mensaje periodístico arquetipo: crónica de interés humano sobre Afganistán; 4.3. Profusa vulneración legal y sistemáticos incumplimientos de la deontología; 4.4. Posibilidades interpretativas: los escenarios bélicos como marcos del dolor. 5. Conclusiones. 6. Referencias.

\section{Fotoperiodismo, violencia y menores}

Mata a uno y espantarás a diez mil, sentenció Sun Tzu, reputado estratega militar chino del siglo VI antes de Cristo. Una aterradora admonición que convierten en máxima de su actuar cuantos despliegan la violencia contra sus congéneres. El reportero gráfico, por contra, parece empecinado en contrapesar la balanza: si muestra el horror 
de la tragedia en el rostro de un menor quizá conmueva a millones de ciudadanos y les movilice para detener la vil agresión del violento. Se comprende así la reflexión de la veterana periodista Maruja Torres: el periodismo gráfico debió nacer "el día en que a los redactores se nos desenfocó el verbo y nos volvimos impotentes para describir la realidad, una realidad para la que, a menudo, una palabra resulta un exceso, y mil no serían suficientes" (Rodríguez-Merchán, 1992: XV). Cuando el 8 de junio de 1972, un avión sudvietnamita bombardeó con napalm la localidad de Trang Bang, allí se encontraba Huynh Cong Ut, fotógrafo de Associated Press. Tomó una instantánea de Kim Phuc, de 9 años, después de que las llamas consumieran sus ropas, mientras corría aterrorizada y dolorida fuera de la población, junto a otros cuatro menores. La imagen, galardonada con un Pulitzer al año siguiente, figura en la historia del fotoperiodismo como alegoría del sufrimiento infantil en las guerras. Se calcula que más de 1.000 millones de niños, de los que un tercio no ha cumplido los 5 años, viven en países o territorios afectados por conflictos armados. Y son menores alrededor de la mitad de los aproximadamente 26 millones de personas desplazadas en la actualidad a causa de la violencia (UNICEF, 2009: 24).

La ausencia de imágenes provoca la desaparición del conflicto (Linde, 2005). Pero, ¿es necesario mostrar el terror en el rostro infantil? Josep Maria Casasús (2002: 12), durante el desempeño de su labor como Defensor del Lector de La Vanguardia, esgrimió una controvertida sentencia de Henri Cartier-Bresson: el público posee derecho a ver toda la realidad. Los escrúpulos de la corrección deontológica llevados hasta sus últimas consecuencias, argumentaba, implicarían velar todos los rostros de niños afectados por situaciones de violencia y dolor, desde las intifadas en Oriente Próximo hasta los de quienes cruzan el Estrecho de Gibraltar en pateras. "Esta extremada manipulación de las fotos no la aceptaríamos la mayoría de los lectores", concluía. Con todo, nunca el profesional puede escapar a la meditación sobre el plano y la composición por la que opta, las consecuencias que su difusión conllevan, y la responsabilidad profesional y personal con las que cargará. No olvidemos que la niñez simboliza con asiduidad la tragedia, natural o accidental, así como el espanto causado por la barbarie y la sinrazón humanas: las que provocaron el mudo grito desgarrador de la niña afgana Tanara Akbari, rodeada de un mar de despojos humanos sanguinolentos tras un atentado suicida en Kabul, que la convirtieron en trágica protagonista de la fotografía de Massoud Hossaini laureada con el Pulitzer 2012.

Estos prestigiosos galardones constituyen un referente de primer orden para ilustrar el binomio violencia-niñez, incluso sin contabilizar los trabajos de reporteros finalistas que abordan idéntico ámbito temático. A título ilustrativo, en los últimos veinticinco años, casi el $25 \%$ de las fotografías premiadas en el ámbito informativo e interpretativo (breaking news photography, feature photography) cuentan con el protagonismo del menor: seis premios asociaban la infancia a los conflictos políticos violentos y las guerras, constituyendo "imágenes arquetipo", una de las variables más

1 Serían los casos, por ejemplo, de "Homecoming”, de Earle L. Bunker (1944); "The Terror of War”, de Huynh Cong Ut (1973); veterano de guerra minusválido con su hijo, de Robin 
significativas de la presente investigación. Existe un estudio prospectivo que apoya esta tendencia en la prensa española (Maciá y Galván, 2008): el 25\% de las fotografías muestra a los menores ligados a la tragedia: conflictos armados $(11,5 \%)$, sucesos sangrientos $(7,5 \%)$ y terrorismo $(6,0 \%)$.

En esa interpretación sucesiva de la realidad social que es el periodismo, que posibilita que la gente pueda entenderla, adaptarse a ella y modificarla (Gomis, 1997: 35 y 43), cuando la prensa representa la brutalidad real, los periódicos "sirven la dieta diaria de violencia bajo la forma preferida de imagen gráfica", concluye Penalva (2002: 397), quien advierte que las imágenes gustan e impactan al público, pero reducen la comprensión del fenómeno, al tiempo que pueden ser objeto de manipulación o descontextualización ${ }^{2}$. Sin olvidar el riesgo de provocar traumas psicológicos en el menor a consecuencia de una indebida información en el relato, la difusión de su imagen o su trato como fuente informativa (Coté y Simpson, 2000; Teichroeb, 2006). Los reporteros gráficos (cámaras, fotógrafos) no parecen ser los principales responsables: solo un $12,5 \%$ considera que contar con el testimonio gráfico sobre un suceso relacionado con la infancia y la violencia es un criterio decisorio de inclusión de la noticia en la cobertura informativa (sin embargo, de 775 periodistas encuestados lo estiman así el 48,9\%) (Fernández-Arribas y Noblejas, 2007: 104 y 119).

La originalidad de esta investigación reside, ante todo, en el propio tema objeto de estudio, apenas abordado hasta el presente en la literatura científica española con la suficiente extensión y calado, pese a las notables implicaciones legales, informativas y deontológicas del fotoperiodismo, máxime cuando cuenta con la presencia de menores. Una posible causa quizá radicara en la conexión entre el poder de los grupos sociales y la definición dominante de violencia que presentan los medios, que explicaría la menor investigación, por ejemplo, sobre las víctimas anónimas, carentes de proyección pública y recursos institucionales (Sampedro y Jerez, 2003: 132-133), pero es un presupuesto teórico cuestionable, carente de evidencias y pruebas empíricas (García-Marín, 2011: 105).

En la producción científica tampoco consta la existencia de un análisis con una muestra tan amplia y específica como la que se examina aquí, virtualidad que coad-

Hood (1977); supervivientes del conflicto Ruanda-Burundi, de Martha Rial (1998); víctimas de la guerra civil en Liberia, de Carolyn Cole (2004); madre que arropa a dos hijos durante un fuego cruzado, de David Leeson y Cheryl Diez Meyer (2004); y niño iraquí víctima de una explosión, de Deanne Fitzmaurice (2005). A las "imágenes símbolo representativas de la síntesis emocional del conflicto" (Rodrigo, 2002: 43), se añade en estos casos la especificidad y trascendencia de la presencia del menor, protagonista invariable dado que la imagen del presente se parece a la del pasado y las del futuro serán como réplicas de las actuales (Sánchez, 2000).

2 "La mayoría de los reportajes fotográficos requiere una cierta cantidad de planteamiento, de adaptación y de dirección de escena, para lograr una coherencia gráfica y editorial. [...] Aquí el fotoperiodista puede sacar a relucir su aspecto más creativo. [...] Si los cambios se convierten en una perversión de la realidad con el único propósito de producir una fotografía más dramática o más comercial, el fotógrafo se ha permitido una licencia artística que no debería darse. Éste es un tipo de falseamiento muy común”, sostiene Smith (2003: 211). 
yuva al carácter innovador del estudio. En escasas ocasiones se ha escrutado la particular relación infancia-fotoperiodismo-violencia, fuera desde la vertiente del derecho (Calatayud, 2000), la deontología (San-Martín, 1996) o la más específica del análisis visual de la imagen (Baeza, 1999; Doménech, 2005). Bien es cierto que desde la perspectiva jurídica la problemática se ha tratado con cierta asiduidad pero eminentemente mediante parámetros casi en exclusiva legales, esto es, a través de la reflexión teórica y la fundamentación jurídica (Alegre, 1997; Azurmendi, 1998; Fernández GonzálezRegueral, 2004 y 2005; Macías, 2009) por lo que adolecen de profundidad en la realidad periodística; a lo sumo, se han presentado análisis de caso útiles y de interés (Torres-Dulce, 2009), pero insuficientes para lo que demanda la sociedad, sea en relación con la protección de los derechos de la infancia y la juventud, sea en la exigencia del respeto a los principios deontológicos de la profesión periodística por los reporteros y las empresas de comunicación.

Con todo, hay que valorar positivamente la atención que dispensan las publicaciones que abordan el tema en el último quinquenio. Desde una perspectiva periodística existen trabajos sustentados en este particular enfoque. Se cuenta ya con algunas indagaciones exploratorias (Maciá, 2011) que han permitido fijar planteamientos teóricos, técnicos y metodológicos para la presente investigación, así como las orientaciones preliminares para el análisis científico de casos (Labio y Manfredi, 2009).

De igual modo, resultan substanciosas y de provecho las ponderaciones emanadas desde las instituciones de autorregulación de los propios medios, en especial de la prensa, como son los defensores del lector (Casasús, 2002: 12; Serrano, 2005: 16 y 2006: 15) o la Comisión de Quejas de la Asociación de la Prensa de Madrid (2007). En ambos casos, desde la tan indispensable autocrítica, se destilan juicios profesionales y deontológicos sobre casos concretos sometidos a un detenido y riguroso análisis.

\section{Objetivo e hipótesis}

En lo que respecta al discurso mediático, perseguimos atender la necesidad de contemplar los distintos géneros discursivos, las formas y los tiempos de presentación (Ericson et al., 1991). Las fotografías atraen más la atención del lector que el texto, más si son en color y, sobre todo, las de gran tamaño ( $>50 \%$ de la superficie de la página), a las que prioritariamente dirigen su vista los destinatarios (Starck et al., 2007).

Las imágenes recopiladas para la exploración versan sobre los conflictos armados a los que se refieren los Convenios de Ginebra (1949) (art. 2) y los Protocolos Adicionales I y II (1977), que incluyen todos los casos de guerra declarada o cualquier otro conflicto armado entre dos o más partes, aun si el estado de guerra no se reconoce por una de ellas. Un conflicto armado comprende cualquier disputa entre dos Estados que conlleva la intervención de miembros de las fuerzas armadas de uno o de ambos Estados. Los conflictos armados nacionales o locales (art. 3) son los que tiene lugar en el territorio de un Estado entre sus fuerzas armadas y las fuerzas disidentes u otros grupos armados organizados que, bajo la dirección de un mando responsable, ejercen sobre una parte de dicho territorio un control tal que les permite realizar operaciones militares sostenidas y concertadas. 
Estas disposiciones prohíben, en cualquier tiempo y lugar, los atentados contra la vida y la integridad corporal, en especial el homicidio en todas sus formas, de los no combatientes (art. 3.1.a). Por consiguiente, porque pertenecen a un ámbito de la realidad, temático y comunicativo diferente, descartamos las fotografías vinculadas al fenómeno del terrorismo, en todas sus formas y ubicaciones: Al Qaeda (Malí, Irak, Pakistán, Yemen, Afganistán), ETA (España), Al Shabab (Somalia), FARC (Colombia), Hezbolá (Israel), Karen (Birmania), los talibanes (India, Pakistán, Afganistán) y el narcoterrorismo (México).

Esta aproximación difiere de los criterios del Correlates of War Project $(\mathrm{COW})^{3} \mathrm{de}$ los que emplean The International Institute for Strategic Studies (IISS) y el Departamento de Investigación sobre la Paz y los Conflictos de la Universidad finlandesa de Uppsala que elabora el Uppsala Conflict Database Program, ya que ambas instituciones incluyen entre los conflictos armados que monitorizan en sus bases de datos cuantos guardan relación con las acciones terroristas. Si no figuran los casos del terrorismo de ETA o del IRA, por ejemplo, es por causa de los criterios cuantitativos que emplean (número de víctimas) y no por su aspecto cualitativo (Gleditsch et al., 2002). Pero la pauta sí coincide, por el contrario, con la conclusión del Comité Internacional de la Cruz Roja (CICR) sobre el concepto de "conflicto armado" conforme al derecho internacional humanitario (2008).

El objetivo sustancial de la investigación se centra en averiguar las características específicas del tratamiento periodístico de las fotografías en las que aparecen menores de edad en relación a la cobertura informativa de conflictos armados en la prensa española de información general. Este análisis persigue integrar la pluralidad de variables presentes, tanto explícitas como implícitas, en el contexto de producción de los mensajes gráficos de la violencia.

Mediante este estudio, y en relación al fotoperiodismo de la naturaleza indicada, se pretenden confirmar o refutar las siguientes hipótesis de trabajo $(H)$ :

H1: Es alta la frecuencia con que aparece el menor en la cobertura informativa internacional de la prensa española, en especial con relación a situaciones de conflicto y violencia armadas.

H2: La distancia geográfica, social, cultural y política implica una mayor indefensión de la infancia ante la acción de los periodistas, lo que se aprecia en una inequívoca e injustificada sobreexposición del menor.

H3: La recurrente desprotección del rostro del menor permite su identificación, lo que vulnera su derecho a la imagen, exponiéndole en determinados casos a una indeseable estigmatización o a sufrir posibles represalias.

3 El propósito del proyecto, ubicado en la Pennsylvania State University desde 2001 e impulsado en 1963 por el politólogo J. David Singer (University of Michigan), es la acumulación sistemática de conocimientos científicos sobre la guerra y los conflictos. De entre sus múltiples bases de datos destaca, a los efectos que interesan para discriminar entre el conflicto armado y el terrorismo, la New COW War Data (1816-2007) sobre conflictos armados intra, inter, extra y no estatales. 
H4: La fotografía que aúna la imagen del menor con el conflicto armado, cuya autoría corresponde mayoritariamente a reporteros gráficos de las principales agencias informativas internacionales, posibilita la amplia dispersión de la instantánea, incrementa su difusión en la prensa, homogeneíza la recepción informativa y constriñe la riqueza interpretativa.

H5: La mayoría de imágenes ( $>50 \%)$ transgrede la normativa legal y vulnera la deontología periodística.

\section{Metodología}

La muestra de análisis comprende una representación significativa de diarios y periódicos españoles de información general, de alcance nacional, tanto de pago como gratuitos. El criterio básico de selección es el número de lectores diario.

Descartamos la prensa económica (Cinco Días, Expansión), tanto por su carácter especializado como por su limitada penetración en el mercado; también se prescinde de la prensa deportiva (Marca, As, Sport, El Mundo Deportivo), por la especificidad de sus contenidos pese al enorme seguimiento de la audiencia. Tampoco examinamos el sector de las revistas, aun cuando resultaría de un interés innegable para el caso que nos ocupa. Pero la inevitable limitación espaciotemporal que afecta a cualquier investigación científica imposibilita abarcar cuanto sería deseable. No obstante, a corto plazo debe estudiarse inexcusablemente este ámbito comunicativo.

Para que la muestra resultase representativa se ha considerado el número de lectores de prensa diaria, tomándose el $3^{\text {er }}$ año móvil del Estudio General de Medios (EGM) correspondiente a 2010 (febrero-noviembre), anualidad al que pertenecen los ejemplares seleccionados. El universo de lectores de prensa de información general y gratuita alcanzaba entonces los 14.994 .000 ciudadanos. Con el fin de que los resultados fueran extrapolables al conjunto del universo observado se necesitaría superar el $50 \%$ de esa cifra con las cabeceras seleccionadas. Al tiempo, convenía mantener un equilibrio entre la prensa histórica de referencia y la gratuita, con discreta amplitud de contenidos y de menor calidad. Por consiguiente, se dejó de lado el gratuito $A D N$, al considerar suficientemente cubierto el cupo de los periódicos de esta categoría.

Tomando en consideración este conjunto de criterios, el marco de la investigación cuenta con un 56,65\% del universo de lectores de prensa: 20 minutos $(2.279 .000$ lectores diarios), El País (1.924.000), Qué! (1.496.000), El Mundo (1.282.000), La Vanguardia (757.000) y $A b c$ (756.000). Se revisaron todas fotografías que se difundieron entre el 2 de enero y el 31 de diciembre.

Compartimos con Rodríguez-Merchán la perspectiva de que la información fotoperiodística constituye la notificación de acontecimientos reales, interpretados visualmente por un fotógrafo y orientados por unos criterios de contingencia (novedad, actualidad, conflicto, prominencia...), mediatizados por varios criterios codificadores (fotográfico, informativo y de difusión) y que produce un mensaje visual que es interpretado por el receptor según su competencia icónica y su conocimiento del contexto (1992: 114). Estos rasgos mensurables, que caracterizan la cobertura gráfica en relación a los conflictos armados, comprenden diversos estratos, de diferente índole, que se perfilaron en 29 clases de variables, agrupadas en cinco niveles: 
a) Jerárquicas, que miden el grado de importancia otorgado al mensaje (publicación, colocación y tamaño de la imagen), así como la calibración de la presencia del menor (número, edad, nacionalidad, justificación de la aparición).

b) Noticiosas, que comprenden el género periodístico, la sección, el tema y asunto que tratan, la naturaleza del pie de foto, así como los criterios de lo noticioso, autoría y el probable carácter arquetípico de la fotografía.

c) Legales y deontológicas. Responden a la normativa legal vigente, la posible violación de los derechos del menor, la transgresión de principios deontológicos y la eticidad de la instantánea.

d) Técnicas, que aluden al plano y ángulo de la toma, el empleo del color y al proceso de edición.

e) Interpretativas. Se centran en el contexto de los hechos, el ámbito de la escena, la vinculación del menor con las personas con las que aparece y el análisis de la comunicación no verbal.

Los datos recopilados se volcaron en hojas de cálculo de Excel, cuyo formato de registro se corresponde con la matriz de análisis. Para el tratamiento de los resultados se empleó el paquete estadístico IBM Statistical Package for the Social Sciences (v. 19.0).

\section{Análisis de los resultados}

\subsection{Señalada y arbitraria aparición del menor como víctima-testigo del conflicto armado}

Se estudiaron 111 fotografías -el 2,99\% del total de imágenes publicadas por los diarios analizados durante el periodo objeto de estudio (3.707)-, en las que aparecían menores de edad (Tabla 1). Las frecuencias de distribución por diario confirman una concordancia con la periodicidad y número medio de páginas de las cabeceras, formándose tres grupos, dos con idénticas proporciones (exiguas, para la prensa gratuita, y medias para El Mundo y El País). Los mayores porcentajes se sitúan entre el 25 y $28 \%$ ( La Vanguardia y $A b c$ ). Significativa es la tendencia general en el peso global informativo del fotoperiodismo con presencia de menores, donde se aprecian indudables coincidencias: porcentajes de entre el 1,4 y $1,7 \%$ en la prensa gratuita, y de entre el 3,1 y $3,6 \%$ en la generalista.

Las imágenes aparecen mayoritariamente en páginas pares $(55,0 \%)$, nunca en contraportada y apenas en portada $(1,8 \%)$. No son cifras que sugieran que se explote de modo sistemático la potencial magnitud de atracción del menor. Sí es notorio, por el contario, la distribución en la franja superior de la página (casi el 65\%), descendiendo proporcionalmente hacia áreas menos llamativas (franja central, 24\%; zona inferior, $11 \%$ ). Esto es, se procura la visibilidad de la instantánea. Pero no se aprecia un abuso al sobredimensionar la imagen, pues la mitad de la muestra ocupa un ancho menor a un cuarto de la mancha $(48,6 \%)$, o se sitúa entre el $25 \%$ y el $50 \%(39,6 \%)$. Solo en torno el $10 \%$ supera en tamaño la media página, a la búsqueda inequívoca del impacto.

Aspecto relevante es la calibración de la presencia del menor. La nacionalidad resulta irrelevante a efectos de cercanía psicológica, dado que ninguno es español. Por 
edades, prima de modo abrumador la infancia $(76,6 \%)$ sobre las categorías de bebés $(9,9 \%)$ y jóvenes $(13,5 \%)$. El motivo por el que aparece permite una interesante lectura, con implicaciones periodísticas, legales y éticas. De entrada, se aprecia una conjunción múltiple de variables, una amalgama de factores. El menor no es protagonista del acontecimiento (11,7\%), sino el afectado por la violencia (27\%), aunque en ocasiones reviste ambas facetas $(9,9 \%)$. En pocos casos aparece como testigo de los hechos o como allegado a los protagonistas. Su presencia no es circunstancial (13,5\%), pero sí se constata que resulta injustificada en demasía $(28,8 \%)$. Se detecta cierto énfasis en el papel de víctima del menor como principal sufriente de la violencia que se genera en los conflictos armados, en los que por su edad pocas veces es actor, pero sí testigo de la brutalidad y del sufrimiento. En los conflictos intraestatales de países periféricos la cobertura se caracteriza por la apelación al humanitarismo (PENALVA, 2002: 404): los medios, mostrando a los damnificados y refugiados de los desastres producidos por la guerra tantean la fibra sensible de la opinión pública para la obtención de ayuda.

Si bien en ocasiones su presencia no la busca el fotógrafo de manera prioritaria, se abusa del recurso al icono del menor-víctima, probablemente por el innegable impacto emocional, con independencia de los condicionantes legales y las connotaciones éticas. Así, el fin justificaría los medios, en línea con la interpretación del ejercicio periodístico por el que aboga el cuestionado advocacy o committed journalism ${ }^{4}$, defendido por aventajados reporteros como Bell, Simpson, Fisk, Salgado, Bauluz o Sánchez. Pero una extrapolación sistémica de la implícita acusación de vulnerar la deontología se antoja exagerada mientras no se aporten pruebas fehacientes del supuesto trastorno personal y profesional que, por ejemplo, Christopher Tulloch atribuye al común de los reporteros de guerra (2011: 76) 5 . Con todo, existe un proceloso debate sobre las consecuencias negativas del tratamiento sensacionalista del dolor como la insensibilización de la audiencia y la hipersensibilización ante la inseguridad (Linde, 2005).

\subsection{Mensaje periodístico arquetipo: crónica de interés humano sobre Afganistán}

El análisis de las variables vinculadas con el tratamiento periodístico de los conflictos armados confirma un resultado previsible: un claro predominio de la crónica $(56,8 \%)$ como mensaje interpretativo característico del corresponsal, enviado especial

4 Esta corriente promueve una cobertura informativa abiertamente favorable a las víctimas de la guerra, planteando un tratamiento periodístico que registre emociones y sufrimiento humano además de consignar los fríos hechos (Tulloch, 2011: 79). El objetivo sería, dado un caso justificado, anteponer la moralidad a la objetividad para acabar con la indiferencia ciudadana.

5 "És innegable que el contacte quotidià amb la misèria humana fa que els corresponsals de guerra pateixin almenys una, quan no totes, de les «tres D» de Leguineche -desequilibrats, divorciats, dipsòmans- i que els portin cap a diversos trastorns i a uns nivells de frustració, cinisme i esgotament tan elevats que poden derivar com a mínim en pràctiques èticament qüestionables i, com a màxim, a l'abandonament definitiu de la professió". 
o reportero de guerra. $\mathrm{Y}$, en segundo término, la fotonoticia como principal producto informativo $(31,5 \%)$ y elocuente, así mismo, su presencia en las secciones de actualidad gráfica $(10,6 \%)$. Otros géneros son exiguos: reportaje $(8,1 \%)$ y géneros de opinión $(1,8 \%)$. El pie de foto cumple con su función informativa $(93,7 \%)$. Dado que el ámbito geográfico noticioso es lejano, la sección habitual en que se insertan imágenes es la de internacional $(73,9 \%)$. Lo que corroboraría el postulado de que uno de los lugares donde más cobertura se ofrece a la violencia es el apartado de noticias internacionales (PENALVA, 2002: 402). La aparición en portada resulta residual (2,7\%), lo que implica que la visión que se ofrece es la del especialista en conflictos mediatizada en buena medida por aquellos acontecimientos que alcanzan la categoría de noticia. El enfoque periodístico se dirige con notable claridad a la contienda de Afganistán (35,1\%), seguido del ancestral conflicto entre Israel y Palestina $(23,4 \%)$ (Tabla 1). A considerable distancia, aparecen la puntual crisis étnica de Kirguizistán ${ }^{6}$ $(9,9 \%)$ y las enquistadas pugnas de Irak $(9,0 \%)$. Destaca el conflicto de los campamentos del Sáhara desmantelados $(8,1 \%)$ que ocupó un significativo espacio debido a unas impactantes fotografías de unos bebés malheridos que la prensa identificó erróneamente como víctimas de ese episodio ${ }^{7}$. En definitiva, se imponen los conflictos eminentemente mediáticos o que brindan un plus de espectacularidad.

${ }^{6}$ Los países en vías de desarrollo únicamente reciben cobertura cuando se producen acontecimientos de impacto; si no se difunden nuevas imágenes, el país queda de nuevo relegado (Penalva, 2002: 405).

7 El episodio, ocurrido en noviembre de 2010, constituye un incontestable paradigma de desatino profesional generalizado en cadena. Primero, la difusión por la agencia Efe a sus clientes de unas fotografías, presuntas estampas de la represión del Ejército marroquí, cuando en realidad correspondían a unos bebés palestinos heridos durante un ataque israelí a Gaza en junio de 2006 (descontextualización). Segundo: tampoco las imágenes eran obra de "activistas saharauis", sino de Ibraheem Abú Mustafa, de la agencia Reuters (inexactitud). Tercero: cuando con posterioridad los diarios admitieron el desmán, fruto de la falta de contraste, en ningún caso destinaron idéntica superficie a la necesaria rectificación (negligencia). La foto había sido tomada del portal saharathawra.org, que reúne a colectivos de apoyo al Sáhara, y que la presentaba como una fotografía de niños saharauis. Cualesquiera que fuesen las causas y el propósito, resulta indudable el incorrecto empleo periodístico de esa instantánea con menores. 
Tabla 1. El menor en las imágenes de la cobertura informativa de conflictos armados (2010)

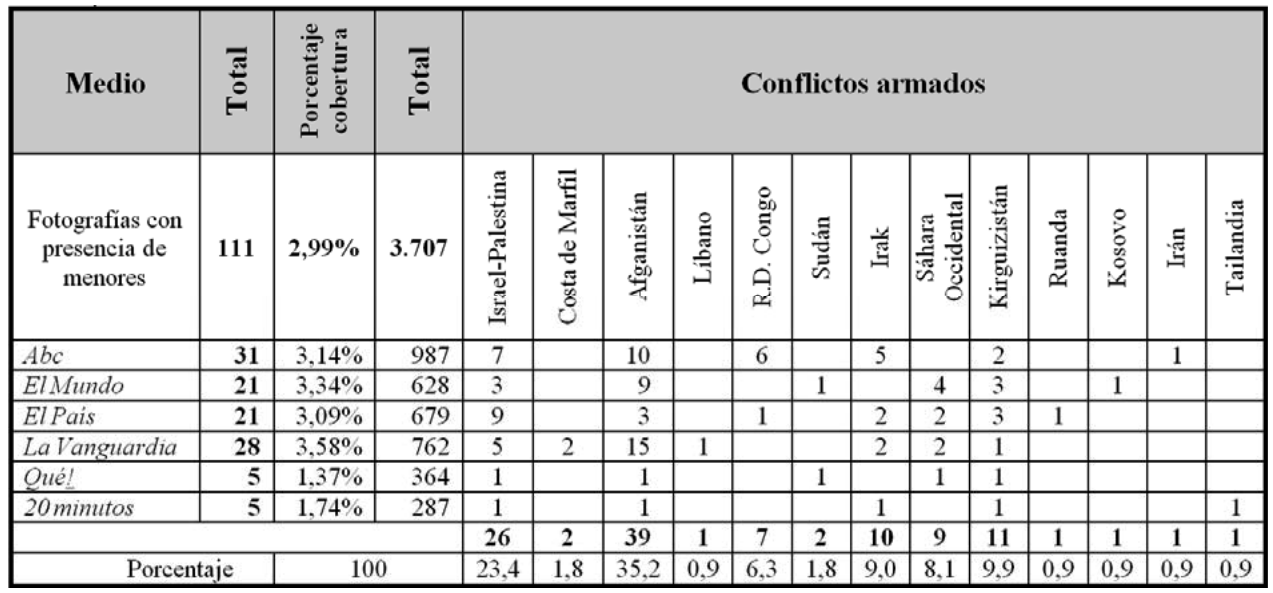

Fuente: Elaboración propia

En relación con los criterios de lo noticioso, el conflicto está presente en el 97,3\% de los casos. La novedad supone un valor connatural a la imagen $(67,6 \%)$, así como el interés humano $(69,4 \%)$, mientras que la excepcionalidad se reduce hasta un $24,3 \%$. La genericidad es un factor presente en la mitad de las ocasiones $(51,4 \%)$. La acción es consustancial a la imagen en un $35,1 \%$ de los acontecimientos mostrados. Dos valores apenas gozan de peso: la prominencia del personaje $(8,1 \%)$ y la proximidad de los acontecimientos $(9,9 \%)$. Estos valores remiten al eminente carácter noticioso del mensaje (noticia, crónica), mediante el que se nos ilustra de la cotidianeidad del sufrimiento de masas de humanos anónimos damnificados por conflictos armados lejanos.

La tipología fotográfica aporta interesantes elementos para la reflexión. La imagen de agencia impera (55,9\%), con un dominio de Associated Press $(21,1 \%)$, sobre Reuters $(17,5 \%)$, Agencia France Press $(15,3 \%)$ y Efe $(11,7 \%)$. Este predominio provoca una homogeneización de la percepción sobre la realidad, dado que encontramos idénticas o similares imágenes en las páginas de los diarios, amén del reflejo, por débil que se estime, de las respectivas líneas editoriales e intereses empresariales de cada corporación. El recurso al archivo posee entidad (10,8\%) aunque resulta ínfimo el uso del banco de imágenes $(1,8 \%)$. La ausencia de firma alcanza un preocupante $9,0 \%$.

En relación con la autoría se aprecia un fenómeno revelador. El $23,4 \%$ de los originales pertenece a reporteros de los diarios, enviados especiales o corresponsales, con la particularidad de que poseen una mirada gráfica que emplea de modo sistemático al menor en la imagen. Sería el caso, como ejemplos representativos, de Mikel Ayestarán $(A b c)$ y Mónica Bernabé (El Mundo).

El carácter arquetípico de la fotografía (conflicto armado $\rightarrow$ violencia $\rightarrow$ víctima $\rightarrow$ menor) se cumple en dos tercios de las instantáneas $(66,7 \%)$ y la intencionalidad en la aparición del menor resulta innegable $(81,1 \%)$. No cabe alegar que su presencia sea aleatoria o circunstancial. 


\subsection{Profusa vulneración legal y sistemáticos incumplimientos de la deontología}

Las implicaciones legales y deontológicas de esta clase de fotoperiodismo son tangibles. En relación con el empleo específico de la imagen del menor, UNICEF establece unos "Principios éticos para informar acerca de la infancia", que constituyen una pauta de primordial interés. Enuncia el principio de no publicar imágenes que, incluso habiendo modificado u omitido los nombres, u ocultado los rostros, puedan suponer un riesgo para el protagonista, su familia o compañeros (I.6). Y, a la hora de escoger una determinada instantánea, exhorta a reflexionar en cómo puede afectar la imagen al protagonista, a su vida y a su historia (II.6). De igual modo, obliga a situar la fotografía del menor dentro de su contexto real (III.2). Y, finalmente, aconseja enmascarar la cara cuando exista un riesgo potencial o real de represalias (que sean o hayan sido niños soldado, solicitantes de asilo, refugiados o desplazados) ${ }^{8}$.

Pese a las urgencias y dificultades inherentes a las circunstancias que rodean su quehacer, el reportero gráfico invariablemente debería tratar de recabar el consentimiento del menor, que goza del derecho a su propia imagen, puesto que es incapaz de prever cómo afectará aquella fotografía que toma ni las consecuencias que tendrá en la vida futura del menor, ni el uso que otros darán a la imagen. Ni siquiera cuando medie la sana intención de denunciar una tropelía o un abuso. Esta detenida consideración debe presidir el actuar del profesional en la toma de todas y cada una de las instantáneas (International Federation of Journalists, 2002: 50-53).

Las variables empleadas en el estudio, que contemplan la normativa vigente en España (Fiscalía General del Estado, 2006), valoran la presencia casual, accesoria o perseguida del menor en la imagen fotoperiodística que se obtiene y difunde. El balance resulta demostrativo: la aparición del menor no es casual $(51,4 \%)$, ni accesoria $(78,4 \%)$ sino buscada $(76,6 \%)$, aunque el posado sea limitado $(14,4 \%)$. Esto es, que lo aleatorio y fortuito resulta tangencial. Se asocia al menor con actividades delictivas en el $9 \%$ de las instantáneas y repetidamente se quebranta su derecho a la propia imagen $(77,5 \%)$.

La perspectiva deontológica arroja cifras del mayor interés. El derecho a la intimidad se viola de modo sistemático $(88,3 \%)$ y no se protege la identidad de los protagonistas $(94,6 \%)$. Tampoco se salvaguarda la identidad de los familiares con los que aparece en niño o joven (36,9\%).

Un aspecto sangrante guarda relación con las recomendaciones y técnicas para enmascarar el rostro de los menores, un aspecto crucial ${ }^{9}$. En el 82,0\% de los casos se expone a las claras su rostro y cuando resulta imposible la identificación, no es porque

8 El Foro Internacional Infancia y Violencia, organizado por el Centro Reina Sofía en Valencia (marzo de 2007), con la participación de 775 profesionales de la información, culminó con unas sugerencias relativas a cómo informar sobre infancia y violencia. Entre las propuestas, figura en preponderante lugar la de respetar la privacidad y confidencialidad de los menores, sean víctimas o agresores. En ninguno de los casos debería publicarse su imagen, lo que podría contribuir a su identificación (Fernández-Arribas y Noblejas, 2007: 149).

9 "No se puede publicar [...] una imagen que pueda poner al niño o niña, sus hermanos o sus compañeros en peligro, incluso cuando se cambien, oscurezcan o no se utilicen sus identidades" (Principio 6, UNICEF, 2005). 
se oculte de modo deliberado (no consta caso alguno de oscurecimiento, velado, difuminado, bandas o pixelado), sino porque se encuentra de espaldas (15,3\%), en escorzo $(13,6 \%)$, por su alejamiento $(6,3 \%)$ o porque otro cuerpo u objeto lo oculta $(17,1 \%)$. Por consiguiente, se violan principios deontológicos en el $83,6 \%$ de las fotografias que mostraron menores anónimos aunque identificables.

\subsection{Posibilidades interpretativas: los escenarios bélicos como marcos del dolor}

El carácter interpretativo se centra en aquellas variables que regulan el contexto de los acontecimientos, el ámbito de la escena, la vinculación del menor con las personas que le acompañan en la imagen y el análisis de la comunicación no verbal.

Existe un recurso generalizado al plano general $(64,9 \%)$, relegando a un segundo término el plano medio $(21,6 \%)$. Aun cuando se emplean, el primer plano $(6,3 \%)$ y el plano americano $(7,2 \%)$ no resultan significativos. El reporterismo gráfico no concentra su mirada tanto en el menor, individualizándole, como en el escenario en que transcurre el conflicto violento y cuantas víctimas lo sufren. La mirada fotográfica se aleja de la singularidad para concentrarse en la colectividad: si en el 4,5\% de imágenes aparece un solo menor, el 66,6\% de estampas incluye desde 4 hasta más de 11 niños o jóvenes al tiempo. No es el dolor personal, sino grupal el que interesa resaltar: la indefensa infancia.

Todas las imágenes se publicaron a color y no consta edición alguna (91,9\%), salvo en el ya mencionado 'caso Sáhara' $(8,1 \%)$. Tampoco se aprecia un recurso retórico en el ángulo de las tomas, por cuanto el encuadre frontal es abrumador $(96,4 \%)$, frente al picado $(2,7 \%)$ y contrapicado $(0,9 \%)$. La interpretación no encuentra asiento, pues, en la técnica ni la edición.

El marco en que aparecen menores rara vez es un ambiente propio (hogar, 5,4\%; colegio, $0,9 \%)$; por lo general, a lo sumo, apropiado: carretera o calle $(45,9 \%)$, hospital $(13,5 \%)$, casa de acogida $(1,8 \%)$ o instalaciones varias $(8,1 \%)$. El menor, a consecuencia del conflicto armado, sufre un nocivo alejamiento del espacio que le corresponde. Pero en un preocupante $27,9 \%$ resultaría perjudicial -campo de batalla $(12,6 \%)$, campo de refugiados $(9,9 \%)$ o campo de prisioneros $(1,8 \%)$-. La recomendación de UNICEF (2005) es nítida: hay que oscurecer la identidad visual de cualquier menor que busca asilo, sea refugiado o esté desplazado (directriz $4^{a}$ ).

Aunque no resulte abrumadora, no extraña que la iconografía guarde estrecha relación con el contexto castrense propio de los conflictos armados: armamento $(28,8 \%)$, uniformes militares $(25,2 \%)$ y banderas $(4,5 \%)$. Una asociación perjudicial a todas luces. También se aprecian vinculaciones con elementos conexos con la violencia -uniformes médicos $(7,2 \%)$, sangre $(6,3 \%)$, vendajes $(6,3 \%)$ o alambre de espino $(4,5 \%)$-, que tiñen de negatividad el mensaje.

Siguiendo los postulados de Paul Ekman (1999), en el lenguaje facial del menor predomina el rostro neutral o ausente $(43,2 \%)$, como propio de su estado de ánimo. No es la tribuna para dirimir ese componente psicológico del fenómeno, confuso reflejo de un estado entre la inconsciencia y la resignación que, no obstante, convendría escrutar. Las lecturas restantes se identificarían con miedo $(17,1 \%)$, tristeza $(13,5 \%)$, alegría $(12,6 \%)$, sorpresa $(6,3 \%)$, cólera $(4,5 \%)$ y disgusto $(0,9 \%)$. En conclusión, domina un semblante que transmite infelicidad. 
No es una práctica recurrente pero interesa aludir a un concepto que bautizo como "efecto ausencia": la presencia en la fotografía del menor, protagonista en solitario, como para destacar su vulnerabilidad, pese a que se intuye que no se encuentra solo. Aun cuando se carezca en este punto de certezas para aseverarlo, es posible que sobrevuele un cierto sensacionalismo emocional (el "suscitar el sentir"), pero no el que se persiga ocultar cuanto sucede mostrando algo que acontece, rasgo característico de una estrategia informativa militar de control de la información (Rodrigo Alsina, 2002: 44 y 45). Un proceder que convendría sin duda investigar sin dilación, por las múltiples incógnitas que suscita.

El desamparo que se apunta aquí guarda más bien relación con la vinculación física y emocional del menor con sus congéneres. Aparece rodeado físicamente de adultos desconocidos más que con sus familiares, con quienes debería encontrarse conforme a su edad. Así, el menor se vincula con el padre $(10,8 \%)$, la madre $(19,8 \%)$ o ambos progenitores $(5,4 \%)$. No obstante, un elemento podría matizar esta interpretación sobre el aparente abandono: desconocemos cuántos de los menores son huérfanos. Quizá una pista que apunta a que ese porcentaje sea significativo es que preferentemente se acompañen de adultos $(50,5 \%)$ frente ancianos $(7,2 \%)$, y aunque sean desconocidos $(49,5 \%)$, con frecuencia son soldados $(27,0)$, una figura que suministra dosis de protección y defensa. Una imagen que, dado el caso, constituiría una denuncia visual de una las consecuencias más sangrantes de los conflictos bélicos.

\section{Conclusiones}

Primera. Se constata una alta frecuencia del recurso periodístico a la imagen del menor para ilustrar situaciones de conflicto y violencia armadas (H1). En la prensa generalista supera el 3\% de las fotografías en las que aparecen menores, por el 1,5\% en la prensa gratuita. Conflicto, novedad e interés humano se erigen en principales criterios de lo noticioso. Los escenarios más recurrentes son Oriente Medio y Afganistán, aproximados a través de la crónica periodística como relato que narra al tiempo que enjuicia una realidad, valorándola tanto mediante la palabra como la fotografía en la que aparecen, sobre todo, los niños. Si bien en ocasiones su presencia no la busca el fotógrafo de manera prioritaria, se abusa del recurso al icono del menor-víctima a escala grupal $(66,6 \%)$ que no individual, probablemente por el innegable impacto emocional en la audiencia, con independencia de los postulados legales y de las connotaciones éticas. En un tercio de las ocasiones su aparición está injustificada. La escenografía que rodea al menor le ubica alejado de su espacio propio, situándolo en las calles $(45,9 \%)$, hospitales $(13,5 \%)$, campo de batalla $(12,6 \%)$ o campos de prisioneros o refugiados $(11,7 \%)$.

Segunda. La distancia geográfica, social, cultural y política implica una mayor indefensión del menor ante la acción de los periodistas, lo que se aprecia en una inequívoca revelación de la identidad y una sobreexposición injustificada de su imagen (H2). La recurrente desprotección del rostro del menor $(82,0 \%)$ permite su fácil identificación, lo que vulnera su derecho a la propia imagen, exponiéndole en determinados casos, a posibles represalias (H3). Cuando no se aprecia su semblante es por causas coyunturales (posición, lejanía). No existe un solo caso en que se oculte su semblante de modo deliberado. El derecho a la intimidad se viola de modo sistemático $(88,3 \%)$, 
no se protege la identidad de los protagonistas $(94,6 \%)$, ni se salvaguarda con asiduidad la de los familiares con los que se retrata al menor (36,9\%).

Tercera. La autoría fotográfica corresponde a profesionales de las principales agencias informativas $(55,9 \%)$, lo que posibilita una copiosa dispersión de la imagen e incrementa su difusión en la prensa. Este fenómeno homogeneíza el flujo informativo y constriñe la pluralidad interpretativa (H4). Solo una cuarta parte de las fotografías ofrece una perspectiva alternativa propia de la respectiva cabecera $(23,4 \%)$.

Cuarta. La mayoría de imágenes $(>50 \%)$ transgrede la normativa legal violando derechos del menor $(78,2 \%)$ y vulnerando principios de la deontología periodística $(83,6 \%)(\mathrm{H} 5)$.

\section{Referencias}

ALEGRE MARTÍNEZ, Miguel Ángel (1997): El derecho a la propia imagen. Madrid, Tecnos.

ASOCIACIÓN DE LA PRENSA DE MADRID (2007): "La protección de la imagen de los menores". Comisión de Quejas. Informe-Resolución 2007/12. Disponible en: http://www.comisiondequejas.com/Resoluciones/Relacion/12.pdf [fecha de consulta: 15 de marzo de 2008].

AZURMENDI, Ana (1998): El derecho a la propia imagen: su identidad y aproximación al Derecho a la información. México, Fundación Manuel Buendía. $2^{\mathrm{a}}$ edición.

BAEZA GALLUR, José (1999): La función ilustrativa de la fotografía en la prensa. Tesis Doctoral. Facultad de Ciencias de la Comunicación. Barcelona, Universidad Autónoma.

CALATAYUD CHOVER, David (2000): La protección de los derechos fundamentales de los menores en los medios de comunicación. Tesis Doctoral. Facultad de Ciencias de la Información. Madrid, Universidad Complutense.

CASASÚS, Josep Maria (2002): "Protección informativa de los menores", en La Vanguardia, 19 de abril, sección "Vivir", p. 12.

COMITÉ INTERNACIONAL DE LA CRUZ ROJA (2008): “¿Cuál es la definición de "conflicto armado" según el derecho internacional humanitario?". Documento de opinión. Marzo. En: http://www.icrc.org/spa/assets/files/other/opinion-paperarmed-conflict-es.pdf [fecha de consulta: 15 de enero de 2012].

COTÉ, William y SIMPSON, Roger (2000): Covering Violence. A guide to ethical reporting about victims and trauma. New York, Columbia University Press.

DOMÉNECH FABREGAT, Hugo (2005): La fotografia informativa en la prensa generalista. Del fotoperiodismo clásico a la era digital. Tesis Doctoral. Facultad de Ciencias Humanas y Sociales. Castellón, Universidad Jaume I.

EKMAN, Paul (1999): "Emotional and conversational nonverbal signals". En: MESSING, Lynn y CAMPBELL, Ruth (eds.): Gesture, Speech and Sign. Londres, Oxford University Press, pp. 45-55. 
ERICSON, Richard V.; BARANEK, Patricia M. y CHAN, Janet. B. L. (1991): Representing Order. Crime, Law and Justice in the News Media. Buckingham, Open University Press.

FERNÁNDEZ ARRIBAS, Javier y NOBLEJAS, Myriam (2007): Cómo informar sobre infancia y violencia. Madrid, Centro Reina Sofía.

FERNÁNDEZ GONZÁLEZ-REGUERAL, María Ángeles (2004): "Derecho a la propia imagen del menor". Actualidad Civil, n $\mathrm{n}^{\mathrm{O}}$ 1, pp. 725-739.

FERNÁNDEZ GONZÁLEZ-REGUERAL, María Ángeles (2005): "Derecho a la propia imagen del menor". En VARIOS AUTORES: Homenaje a Íñigo Cavero Lataillade. Valencia, Tirant lo Blanch, pp. 583-603.

FISCALÍA GENERAL DEL ESTADO (2006): Instrucción 2/2006, de 15 de marzo, sobre el Fiscal y la protección del derecho al honor, intimidad y propia imagen de los menores.

GARCÍA MARÍN, Javier (2011): "Conflictos y cobertura mediática: una aproximación desde la comunicación política". En: VARIOS AUTORES: Conflictos, opinión pública y medios de comunicación. Análisis de una compleja interacción. Cuadernos de Estrategia, $n^{\circ}$ 148. Madrid, Ministerio de Defensa, pp. 98-128.

GLEDITSCH, Nils Petter; WALLENSTEEN, Peter; ERIKSSON, Mikael; SOLLENBERG, Margareta y STRAND, Hâvard (2002): “Armed Conflict 1946-2001: A New Dataset". Journal of Peace Research, no 39, pp. 615-637.

GOMIS, Lorenzo (1997): Teoría del Periodismo. Cómo se forma el presente. Barcelona, Paidós.

INTERNATIONAL FEDERATION OF JOURNALISTS (IFJ) (2002): Putting Children in the Right. Guidelines for Journalists and Media Professionals. Bruselas, IFJ.

LABIO, Aurora y MANFREDI, Antonio (2009): “Análisis del tratamiento gráfico de las noticias sobre infancia en contextos de crisis humanitarias". En: GONZÁLEZ, A.; LABIO, A. y MANFREDI, A.: Medios de comunicación y protección de la infancia en contexto de crisis humanitarias. Sevilla, Save the Children España, pp. 60-75.

LINDE, Antonio (2005): "Reflexiones sobre los efectos de las imágenes de dolor, muerte y sufrimiento en los espectadores". Comunicar, Vol. XIII, $\mathrm{n}^{\circ} 25$.

MACIÁ-BARBER, Carlos (2011): "La espinosa conjunción de políticos, menores y reporteros: legalidad y eticidad en la fotografía de prensa". Anàlisi. Quaderns de Comunicació i Cultura, $\mathrm{n}^{\mathrm{o}}$ 42, pp. 33-63.

MACIÁ-BARBER, Carlos y GALVÁN, María Ángeles (2008): "Deontología periodística de la fotografía en prensa: aproximación al tratamiento de la imagen de los menores de edad". En: EGÚZQUIZA, I. y VIDAL, V. (Coord.): El derecho a la información judicial. Valencia, Fundación COSO, pp. 287-303.

MACIAS CASTILLO, Agustín (2009): "Protección de la imagen de los menores". En: LLAMAS POMBO, Eugenio (Coord.): Nuevos conflictos del derecho de familia. Madrid, La Ley, pp. 623-646. 
PENALVA, Clemente (2002): "El tratamiento de la violencia en los medios de comunicación". Alternativas: cuadernos de trabajo social, n 10, pp. 395-412.

RODRIGO ALSINA, Miquel (2002): "El periodismo bélico o la guerra al periodismo". Signo y pensamiento, Vol. XXI, n 40, pp. 42-51.

RODRÍGUEZ MERCHÁN, Eduardo (1992): La realidad fragmentada. Una propuesta de estudio sobre la fotografía y la evolución de su uso informativo. Tesis Doctoral. Facultad de Ciencias de la Información. Madrid, Universidad Complutense.

SAMPEDRO, Víctor y JEREZ, Ariel (2003): "Violencia y medios de comunicación. Una revisión teórica desde los movimientos sociales". Documentación Social, $\mathrm{n}^{\circ}$ 131, pp. 127-156.

SÁNCHEZ, Gervasio (2000): Niños de la guerra. Barcelona, Blume.

SAN MARTÍN PASCAL, María Ángeles (1996): Código ético y deontológico para la imagen y fotografia periodística. Madrid, Trigo.

SERRANO, Sebastián (2005): "La imagen de los niños", en El País, sección Opinión: "El defensor del lector" (p. 16).

SERRANO, Sebastián (2006): "Niños invisibles”, en El País, sección Opinión: “El defensor del lector" (p. 15).

SMITH, Eugene W. (2003): "Fotoperiodismo". En: FONTCUBERTA, Joan (Ed.): Estética fotográfica. Barcelona, Gustavo Gili.

STARCK, Pegie, EDMONDS, Rick y QUINN, Sara (2007): "Eyetraking the News: A Study of Print and Online Reading". St. Petersburg, FL., Poynter Institute.

TEICHROEB, Ruth (2006): "Covering children and trauma. A guide for journalism professionals", en Dart Center for Journalism and Trauma, Estados Unidos. Disponible en: http://dartcenter.org/files/covering_children_and_trauma_0.pdf [fecha de consulta: 30 de junio de 2012].

TORRES-DULCE LIFANTE, Eduardo (2009): "Imágenes de menores y libertad de información". Diario La Ley, no 7.241.

TULLOCH, Christopher D. (2011): “Advocacy journalism: últimes notícies del debat sobre l'ètica periodística i la cobertura del conflicte armat". Periodística, $\mathrm{n}^{\circ} 13$, pp. $75-85$.

UNICEF (2005): Principios éticos para informar acerca de la infancia. En: http://www.unicef.org/spanish/media/media_tools_guidelines.html [fecha de consulta: 17 de junio de 2011].

UNICEF (2009): Estado Mundial de la Infancia. Informe especial $\left(20^{\circ}\right.$ aniversario de la Convención sobre los Derechos del Niño). Nueva York, Unicef. 